Hope College

Hope College Digital Commons

Faculty Publications

8-2017

\title{
Virtue, Positive Psychology, and Religion: Consideration of an Overarching Virtue and an Underpinning Mechanism
}

\author{
Lindsey M. Root Luna \\ Hope College, rootluna@hope.edu \\ Daryl R. Van Tongeren \\ Hope College, vantongeren@hope.edu \\ Charlotte vanOyen-Witvliet \\ Hope College,witvliet@hope.edu
}

Follow this and additional works at: https://digitalcommons.hope.edu/faculty_publications

Part of the Psychology Commons, and the Religion Commons

\section{Recommended Citation}

Repository citation: Root Luna, Lindsey M.; Van Tongeren, Daryl R.; and vanOyen-Witvliet, Charlotte, "Virtue, Positive Psychology, and Religion: Consideration of an Overarching Virtue and an Underpinning Mechanism" (2017). Faculty Publications. Paper 1463.

https://digitalcommons.hope.edu/faculty_publications/1463

Published in: Psychology of Religion and Spirituality, Volume 9, Issue 3, August 1, 2017, pages 299-302. Copyright @ 2017 American Psychological Association.

This Article is brought to you for free and open access by Hope College Digital Commons. It has been accepted for inclusion in Faculty Publications by an authorized administrator of Hope College Digital Commons. For more information, please contact digitalcommons@hope.edu. 
Running head: OVERARCHING VIRTUE AND UNDERPINNING MECHANISM

Root Luna, L. M., Van Tongeren, D. R., \& Witvliet, C. V. O. (2017). Virtue, positive psychology, and religion: Consideration of an overarching virtue and an underpinning mechanism. Psychology of Religion and Spirituality 9(3), 299-302.

doi.10.1037/rel0000127

Virtue, Positive Psychology, and Religion: Consideration of an Overarching Virtue and an Underpinning Mechanism

Lindsey M. Root Luna, Daryl R. Van Tongeren, \& Charlotte van Oyen Witvliet

Hope College

Word Count: 3,133

Author Note

Corresponding Author: Lindsey Root Luna, Psychology Department, Hope College, 35 E. 12th

St., Holland, Michigan 49422-9000, USA; Phone (616) 395-7727; Fax (616) 395-7163;

rootluna@hope.edu.

Co-Authors: Daryl R. Van Tongeren, Charlotte vanOyen Witvliet Psychology Department, Hope College

Acknowledgements: We are grateful to Heidi Giannini for her insight regarding these ideas and feedback on an earlier draft of this commentary. 
Running head: OVERARCHING VIRTUE AND UNDERPINNING MECHANISM

The study of virtue highlights a rich intersection between positive psychology and religion. The virtues of humility, patience, and gratitude, examined in three target articles within this special issue (Davis, Hook, McAnnally-Linz, Choe, \& Placares, this issue; Schnitker, Houltbert, Dryness, \& Redmond, this issue; Van Cappellen, this issue), are all valued within both religious systems and positive psychology. Within the psychological literature, humility and patience have been most commonly defined as personality constructs (Davis et al., 2011; Schnitker, 2012), and gratitude has often been described as a moral emotion that can be a characteristic response of a person (McCullough, Kilpatrick, Emmons, \& Larson, 2001). The Christian philosopher Aquinas described all three as moral virtues, related to the Cardinal Virtues of temperance, fortitude, and justice, respectively. Aquinas structured much of his virtue theory on the work of Aristotle (Aristotle, 1999), whose work has been theoretically formative for researchers in positive psychology (e.g., Peterson \& Seligman, 2004, pp. 9-10). However, Aristotle did not include any of the constructs named here in his taxonomy of virtues. Rather, these constructs were brought into the umbrella of virtue by thinkers from religious traditions. Although psychologists have ignored this broader context at times, we believe an interdisciplinary framework - including both religious and philosophical perspectives - has the potential to strengthen the empirical work on virtue, as well as further clarify its connections with religion and spirituality. .

As noted in the target articles, these virtues have had much broader appeal beyond the realm of religion and spirituality. The advent of positive psychology in the empirical literature, advanced through funding from the John Templeton Foundation and the Fetzer Institute, has spurred on investigations into various virtue constructs. One example often pointed to within the positive psychology literature is forgiveness. Researchers have examined the situational and 
Running head: OVERARCHING VIRTUE AND UNDERPINNING MECHANISM

dispositional elements that predict forgiveness (for a meta-analysis, see Fehr, Gelfand, \& Nag, 2010), the process of forgiveness unfolding over time (e.g., McCullough, Root Luna, Berry, Tabak, \& Bono, 2012), the physiological outcomes of forgiveness in an experimental context (e.g., Witvliet, Hofelich, Hinman, \& Knoll, 2015), the impact of priming forgiveness (Van Tongeren, Welch, Davis, Green, \& Worthington, 2012), the situations when forgiveness may be maladaptive or contraindicated (e.g., McNulty \& Fincham, 2009), and effective ways to engage forgiveness in a therapeutic context (for a meta-analysis, see Wade, Hoyt, Kidwell, \& Worthington, 2014). Although not exhaustive, this brief list demonstrates both the breadth and depth of research in forgiveness, above and beyond correlations and well-being. Unfortunately, forgiveness is an exception, rather than the norm within positive psychology. As suggested by the authors in this special issue, more depth is needed in empirical examinations of virtue.

Along with deepening the work within individual virtue constructs, however, we believe virtue researchers could further advance the field by considering overarching themes that have emerged in empirical research on virtue. Two possible approaches for empirical investigation center on related but distinct critiques. The first critique is that the approach commonly used by positive psychologists fails to consider or integrate the unity of virtue thesis (Banicki, 2014; Kristjánsson, 2010), which suggests that exploring an overarching construct representing virtue may be fruitful. The second, related critique addresses the character types put forth by Aristotle (1999), which are rarely addressed by psychologists (Fowers, 2008); an acknowledgement of character types may lead to an understanding of the underlying mechanisms of virtue, as we will argue below. Put simply, we suggest that future work should consider whether there is an overarching construct and underlying mechanism common to all virtues. 
Running head: OVERARCHING VIRTUE AND UNDERPINNING MECHANISM

\section{General Virtue: An Overarching Construct}

Thus far, little empirical work has considered the unity of virtue thesis. Both philosophers (Kristjánsson, 2013) and Christian psychologists (Nelson \& Slife, 2016) have expressed concerns that the individual constructs often studied by positive psychologists and named virtues—such as gratitude, humility, and patience in this volume-rely on one another. But beyond simply suggesting that virtues are strongly related with one another, these thinkers propose that to be virtuous requires that one has all of the virtues (Aristotle, 1999). That is, virtue may be a common latent factor expressed in various character strengths or more narrowly sliced behaviors, such as humility, patience, and gratitude. This proposition suggests that an overarching factor, above and beyond individual virtues, is a worthwhile construct for investigation.

Studies within positive psychology have already demonstrated connections among the virtues, or a tendency for them to correlate. For example, gratitude and forgiveness have been shown to share predictive variance regarding well-being and adaptive personality traits (e.g., Breen, Kashdan, Lenser, \& Fincham, 2010; Toussaint \& Friedman, 2009). Prompting forgiveness with an imagery paradigm resulted in greater expressed gratitude by people who imagined an interpersonal transgression (e.g., Witvliet, Worthington, Root, Sato, Ludwig, \& Exline, 2008; Witvliet, Knoll, Hinman, \& DeYoung, 2010). More directly related to this volume, Schnitker et al. (this issue) described patience and humility as intertwined in the Christian tradition.

We wonder if there might be a common, higher-order factor of virtue, from which specific expressions of particular virtues (e.g., humility, gratitude) might arise. Given that previous research has found connections between specific virtue constructs, the unity of virtue 
Running head: OVERARCHING VIRTUE AND UNDERPINNING MECHANISM

implies a single higher-order factor, similar to $g$ in general intelligence. That is, if someone is virtuous, we would expect them to score relatively high on various measures of virtues. So, it may be possible that $V$ might represent general virtuousness. Accordingly, researchers studying particular virtuous expressions might be assessing, in part, an individual's overarching virtue.

The examination of a higher-order construct within individual virtues is not a new idea, even among empirical psychologists. Using the VIA Inventory of Strengths (Peterson \& Seligman, 2004), several studies have examined the higher-order structure of the scale (e.g., Macdonald, Bore, \& Munro, 2008), with one study revealing a hierarchical structure including a single factor labeled “good character” (McGrath, 2015). Beyond this single study, we are unaware of a systematic effort within positive psychology to determine what overarching concept (V) might represent the concepts currently described as virtues.

Aristotle’s (1999) master virtue of phronesis, or practical wisdom, was described, in part, as the ability to properly apply the other virtues in a variety of contexts (Fowers, 2008; Kristjánsson, 2010). Aquinas (2008) agreed with Aristotle that practical wisdom was essential for flourishing. The disposition to act rightly (virtue) requires understanding of the proper time and place for the right action. From this perspective, considering character strengths as isolated virtues is a dramatic departure from Aristotle and Aquinas. Rather, from an Aristotelian and Thomistic perspective, a virtuous person would have at her disposal a repertoire of virtuous actions that may be expressed in situationally appropriate contexts.

In an effort to empirically investigate whether practical wisdom might be rightly called the master virtue, Krause and Hayward (2014) used a structural equation model to identify a second-order factor they called practical wisdom, which was in turn related to hope and selfesteem. Although it is possible a second order factor could represent practical wisdom, it is also 
Running head: OVERARCHING VIRTUE AND UNDERPINNING MECHANISM

possible that this factor represents something quite unlike a virtue. For example, it might represent a genetic predisoposition to what Aristotle (1999) called "natural virtue.” Although a person with natural virtue may choose the correct course of action, he lacks the understanding that comes with true virtue and often misapplies his good intentions. For example, he may be helpful to others naturally, which would generally have a positive impact. However if he provides "help” to work partners automatically_even when they have asked for the opportunity to work independently—-he will likely produce a negative outcome.

Although statistical methods make it challenging to define a higher-order factor with complete certainty, best practices allow researchers to increase confidence regarding its characteristics. First, researchers could investigate whether this higher order structure holds across additional samples, character traits, and virtue scales. Second, determining whether this construct (if replication reveals that it is consistent) represents practical wisdom, or some other construct, would involve careful consideration of convergent and divergent validity. Assuming that a higher order master virtue construct $(V)$ represented phronesis, researchers would need to identify which experiences and values would be expected to relate to practical wisdom, but not to other possible higher-order factors. For example, we would expect flourishing to more closely relate to this higher order practical wisdom factor $V$ than to individual virtue measures such as patience, humility, and gratitude, if Aristotle and Aquinas were indeed correct in their thinking about the master virtue.

Beyond the substance of this practical wisdom factor — should it exist — the context of this volume prompts the question of whether religion and spirituality might be linked with a higher order construct. In two studies of mid- to late-life adults, self-reported practical wisdom was associated with more attendance at Christian worship services, hope, and life satisfaction (Krause 
Running head: OVERARCHING VIRTUE AND UNDERPINNING MECHANISM

\& Hayward, 2014, 2015). Although these studies did not include a range of character strengths, the specific measure of practical wisdom was associated with both religion and self-reported well-being.

\section{Self-Regulation: An Underpinning Mechanism}

The second Aristotelian idea that has received little attention from psychologists regarding virtue is the existence of character types (Fowers, 2008). Most commonly, when character is spoken of, a virtuous character is implied (e.g., she is a person of character). Of particular interest in the realm of positive psychology is the role of continence. Aristotle clearly differentiated between the continent person who often behaves in a way that looks virtuous, but against appetite or desire (e.g., suppressing the desire to boast or brag about accomplishments). In contrast, the virtuous person not only behaves in a way that looks virtuous, but truly is virtuous as the behavior is in line with appetite or desire (e.g., lacking the desire to boast or brag about accomplishments).

Clearly, this is a difficult distinction when using an empirical approach as it is far more challenging to accurately measure motivation and process than behavior. However, beyond this measurement issue, we believe the separation of continence from virtue draws attention to an opportunity. If virtue truly requires that appetite or desire is in line with behavior, then the role of self-control needs to be reexamined in relationship to character strengths and virtue. Self-control has been suggested elsewhere as the "master virtue” (e.g., Baumeister \& Exline, 1999; Green \& Van Tongeren, 2012), with positive psychologists often placing self-control squarely with other character strengths (Peterson \& Seligman, 2004). But if the Aristotelian conceptualization of continence is taken seriously, and considered as separate from virtue, then conceptually selfcontrol cannot function in this way. The continent person must use effortful self-control; the 
Running head: OVERARCHING VIRTUE AND UNDERPINNING MECHANISM

virtuous person does not require effortful self-control, as his or her desire is in line with virtuous behavior. This raises an interesting question: what underlying mechanism might prompt virtue, above and beyond continence?

One possible contender for the mechanism underlying virtue is self-control's close relative: self-regulation. Although self-regulation and self-control are sometimes used interchangeably, self-regulation can involve not only effortful control, but also automatic processes (Carver \& Scheier, 2016; Papies \& Aarts, 2016). It is the automatic processes of selfregulation, regarding goal pursuit, self-monitoring, motivation, and behavior (Carver \& Scheier; McCullough \& Willoughby, 2009) that may have a role to play for the virtuous person. Differentiating effortful self-control from the construct of self-regulation-particularly the components that occur automatically and without conscious control—may provide the opportunity to isolate this mechanism.

We see self-regulation as key to the virtues in the articles we reviewed: humility requires restraining selfish impulses for praise and credit in order to act modestly and prioritize the needs of others, patience requires forgoing strong impulses toward immediate gratification for the consideration of a larger goal or purpose, and gratitude requires looking beyond oneself to consider the benefits one has received from others. We contend that at their core, all virtues require some degree of self-regulation.

Authors of two of the target articles explicitly explored connections between two virtues and self-regulation (Davis et al., this issue; Schnitker et al., this issue): humility and patience. Davis and colleagues connect humility to self-regulation in their review and describe how humility is correlated with self-regulation. However, they also present the hypothesis that humility enhances self-regulation in relationships. If self-regulation truly does underlie virtue, 
Running head: OVERARCHING VIRTUE AND UNDERPINNING MECHANISM

then perhaps self-regulation enhances humility, resulting in more positive relationships, rather than the other way around.

Regarding patience, Schnitker et al. (this issue) provide a theoretical foundation for patience that rests squarely on identity and personality traits that support adaptation, like emotion regulation, which is a component of self-regulation. Similar to Davis et al. (this issue), Schnitker and colleagues proposed and tested a model with reappraisal—an adaptive emotion regulation strategy-as a result of predicted outcome, rather than the inverse. However, the Emotion Regulation Questionnaire (Gross \& John, 2003) was used and consists of items that stress effortful control, so it may be a better indication of self-control than the implicit self-regulation proposed here as an underlying process.

Schnitker et al.’s model also included proposed relationships with spiritual transcendence, religious meaning, and spiritual practices. They proposed that religious meaning and spiritual practices both impacted personality through religious reappraisal and habits, respectively. The connections between religion and self-regulation have been explored in a review (McCullough \& Willoughby, 2009), which suggested that religion is connected with the relevant components of self-regulation (i.e., goals selection, self-monitoring, self-regulatory strength, and self-regulatory behaviors). One reasonable hypothesis regarding the direction of this relationship is that formation within religious and spiritual traditions facilitates selfregulation, which undergirds virtue.

\section{Coda}

The work presented in the target articles of this special issue represents precisely the direction needed in the study of virtue within positive psychology broadly, and at the intersection of religion and spirituality more specifically. As researchers delve more deeply into the specifics 
Running head: OVERARCHING VIRTUE AND UNDERPINNING MECHANISM

of individual character strengths, the danger can be to "lose the forest for the trees." We sought to offer a broader perspective of virtue to help situate these findings, as well as catalyze future research, by suggesting future work examine general virtuousness as an overarching construct and self-regulation as an underlying mechanism. We hope that the conceptualizations and methodology present here can also be brought to bear in fruitful ways to further an understanding of virtue, positive psychology, and religion. 
Running head: OVERARCHING VIRTUE AND UNDERPINNING MECHANISM

\section{References}

Aquinas. (2008). The summa theologica of St. Thomas Aquinas (2nd ed.; Fathers of the English Dominican Province, Trans.). Retrieved from http://newadvent.org/summa/

Aristotle. (1999). Nicomachean ethics (2nd ed.; T. Irwin, Trans.). Indianapolis, IN: Hackett Publishing Company.

Banicki, K. (2014). Positive psychology on character strengths and virtues. A disquieting suggestion. New Ideas in Psychology, 33, 21-34. doi:10.1016/j.newideapsych. 2013.12.001

Breen, W. E., Kashdan, T. B., Lenser, M. L., \& Fincham, F. D. (2010). Gratitude and forgiveness: Convergence and divergence on self-report and informant ratings. Personality and Individual Differences, 49, 932-937.

Carver, C. S. \& Scheier, M. F. (2016). Self-regulation of action and affect. In K. Vohs \& R. Baumeister, Eds). Handbook of self-regulation: Research, theory, and applications (3rd Ed., pp. 3-23). New York, NY: Guildford.

Fehr, R., Gelfand, M. J., \& Nag, M. (2010). The road to forgiveness: a meta-analytic synthesis of its situational and dispositional correlates. Psychological Bulletin, 136(5), 894-914.

Fowers, B. J. (2008). From continence to virtue: Recovering goodness, character unity, and character types for positive psychology. Theory \& Psychology, 18, 629-653.

Green, J. D., \& Van Tongeren, D. R. (2012). Self-regulation and a meaning-based approach to virtues: Comments on Hampson’s Habitus. Edification, 6, 19-23.

Krause, N., \& Hayward, R. (2014). Virtues, practical wisdom, and psychological well-being: A Christian perspective. Social Indicators Research, 122, 735-755. doi:10.1007/s11205014-0709-4 
Running head: OVERARCHING VIRTUE AND UNDERPINNING MECHANISM

Krause, N. \& Hayward, R. (2015). Assessing whether practical wisdom and awe of God are associated with life satisfaction. Psychology of Religion and Spirituality, 7, 51-59. doi: 10.1037/a0037694

Kristjánsson, K. (2010). Positive psychology, happiness, and virtue: The troublesome conceptual issues. Review of General Psychology, 14, 296-310. doi:10.1037/a0020781

Kristjánsson, K. (2013). Virtues and vices in positive psychology. Cambridge University Press. Macdonald, C., Bore, M., \& Munro, D. (2008). Values in action scale and the Big 5: An empirical indication of structure. Journal of Research in Personality, 42, 787-799.

McCullough, M. E., Root Luna, L. M., Berry, J. W., Tabak, B. A, \& Bono, G. (2010). On the form and function of forgiving: modeling the time-forgiveness relationship and testing the valuable relationships hypothesis. Emotion, 10, 358-376. doi:10.1037/a0019349

McCullough, M. E., \& Willoughby, B. L. (2009). Religion, self-regulation, and self-control: Associations, explanations, and implications. Psychological Bulletin, 135, 69-93.

McNulty, J. K., \& Fincham, F. D. (2012). Beyond positive psychology? Toward a contextual view of psychological processes and well-being. American Psychologist, 67, 101-110.

Nelson, J. M., \& Slife, B. D. (2016). A new positive psychology: A critique of the movement based on early Christian thought. The Journal of Positive Psychology.

Papies, E. K. \& Aarts, H. (2016). Automatic self-regulation: From habit to goal pursuit. In K. Vohs \& R. Baumeister, Eds). Handbook of self-regulation: Research, theory, and applications (3rd Ed., pp. 203-222). New York, NY: Guildford.

Peterson, C., \& Seligman, M. E. P. (2004). Character strengths and virtues: A handbook and classification. New York, NY: Oxford University Press. 
Running head: OVERARCHING VIRTUE AND UNDERPINNING MECHANISM

Toussaint, L., \& Friedman, P. (2009). Forgiveness, gratitude, and well-being: The mediating role of affect and beliefs. Journal of Happiness Studies, 10, 635-654.

Van Tongeren, D. R., Welch, R. D., Davis, D. E., Green, J. D., \& Worthington Jr, E. L. (2012).

Priming virtue: Forgiveness and justice elicit divergent moral judgments among religious individuals. The Journal of Positive Psychology, 7, 405-415.

Wade, N. G., Hoyt, W. T., Kidwell, J. E., \& Worthington Jr, E. L. (2014). Efficacy of psychotherapeutic interventions to promote forgiveness: A meta-analysis. Journal of Consulting and Clinical Psychology, 82, 154.

Witvliet, C.V.O., Hofelich Mohr, A.J., Hinman, N. G., Knoll, R. W. (2015). Transforming or restraining rumination: The impact of compassionate reappraisal versus emotion suppression on empathy, forgiveness, and affective psychophysiology. Journal of Positive Psychology, 10, 248-261.

Witvliet, C. V. O., Knoll, R. W., Hinman, N. G., \& DeYoung, P. A. (2010). Compassionfocused reappraisal, benefit-focused reappraisal, and rumination after an interpersonal offense: Emotion-regulation implications for subjective emotion, linguistic responses, and physiology. The Journal of Positive Psychology, 5, 226-242.

Witvliet, C.V.O., Worthington, E.L., Root, L.M., Sato, A.F., Ludwig, T.E., \& Exline, J.J. (2008). Retributive justice, restorative justice, and forgiveness: An experimental psychophysiology analysis. Journal of Experimental Social Psychology, 44, 10-25. 